\title{
Raising your profile on a grant application
}

Judy Robertson \& Barry Lovern

(With thanks to Catherine Burns

for her comments.)
Research Councils UK says that female principal investigators are disproportionately unsuccessful in grant applications (RCUK, 2016). Assuming that the imbalance is for reasons other than the quality of the research, we should look to redress this. One way to approach this is to ensure that the application and review process itself is not biased (see How to become a better scientific evaluator).

This is a companion recipe, written for any individual who is applying for grants, and would like to know what they can do to increase the likelihood of success.

\section{Ingredients}

- Confidence in your capabilities and the value of your achievements to date.

- Assertiveness: if you have done great work which implies the potential to do further great work, say so.

- $\quad$ Recipe Dealing with imposter syndrome.

\section{Method}

1. Carefully read the call and check that your idea fits the terms. Take the time to properly understand what is required and the remit of the funder. Manage your expectations: funding schemes are very competitive and the chances are high that you will not succeed first time. This is not a reason to despair, though. Before you begin writing, think of Plan B and Plan C with other funding schemes just in case this one is not awarded.

2. Review successful grant applications for the funding scheme you are applying to (your research support office should be able to provide you with these). Analyse how the applicant has described their previous experience and achievements, and how they have described the importance of the research idea. Read the guidelines for each section carefully so you know what the funder is expecting.

\section{Go for your full research vision.} Funders are looking for confidence and ambition so don't compromise for the sake of the budget. Consider how much to apply for. In an analysis of the monetary value of grants awarded to male and female researchers by the UK funder Wellcome Trust, it was found that women were awarded on average $£ 44,735$ less than men (Bedi et al., 2012). As the authors point out, because the funder normally awards the amount which was requested for successful proposals, this suggests that women are less ambitious about the amount for which they apply. If you're a woman, consider whether you have applied for enough; if you're a man, weigh up whether the funders would consider the amount economical! 
4. Write your application. Bear in mind that you are writing a business case rather than a journal article. Assume it will be read by an intelligent person who may not have disciplinary expertise. You will need to make it clear for them.

\section{Pay particular attention to sections} which describe the researcher. In a study of applications to the Netherlands Organization for Scientific Research, women received slightly (but statistically significantly) lower numerical ratings of the applicant's research profile, but not for the content of the proposal itself (van der Lee \& Ellemers, 2015). Review your application and highlight any sections which could seem to minimise or downplay the importance of the research idea or your experience. Be careful about your choice of words, particularly in the adjectives in your track record. Language that is often used to describe women includes 'grind' adjectives like 'conscientious', 'trustworthy', 'reliable', as opposed to those used about men, 'stand-out' adjectives like 'brilliant', 'excellent', first-rate' (Dutt et al., 2016). It's a grant proposal - you're expected to claim brilliance. Similarly, if you have to include a letter of recommendation with your application, tactfully make sure your referee knows to avoid 'grind' adjectives. Experiment with writing track record sections in a confident way. Play with phrasing and language even if it feels as if you are 'talking yourself up'. Before investing in your project, the funders need to know you will deliver what you plan. You can edit systematically to make every statement more assertive once you have completed the main draft.

6. You may find it helpful to list the achievements which are relevant for the application and note the objective evidence for these. Do not cross the line to sounding aggressive. Similarly, on the first draft, do not be afraid of sounding arrogant - this can be toned down later. Any seemingly arrogant statement that can be backed up with objective evidence is fair game.

7. Reshape your CV for every application to tailor it to the funding call. Show that you have the experience in people management and budgetary skills from your previous work.

8. Get feedback from a 'critical friend' or a more senior mentor who has experience in writing successful research grants. Do they think it sounds over the top or inaccurate? Or is it pitched at the right level? Are there relevant achievements you've missed or not drawn enough attention to? Leave time to make any changes they suggest to the proposal before the deadline. 
9. Leave it in a drawer for a week and then re-read it, pretending it is a colleague's application. What can sound over the top when you are talking about yourself can seem perfectly acceptable if someone else writes it. Are there any further adjustments to be made?

10. Complete your final proofs and edits as you normally would and submit.

11. Be a critical friend to other colleagues who may be finding this aspect of writing applications challenging.

12. If you have an opportunity to respond to reviewers. Everyone feels upset at reviewer criticism, but don't be defensive in your response. If you find yourself typing "Reviewer $X$ missed the point", delete it and think about how you could make the point clearer. Run your reply past an experienced colleague before you submit it. Ask them to be neutral or critical.
13. If you get rejected, curse and howl, but don't give up! Resubmit the proposal if the funder allows, or put Plan B into action by reworking the application for a different funder. In the Netherlands study, although there was a gender gap in applications submitted for the first time, this difference had evened out for proposals which were resubmissions (van der Lee \& Ellemers, 2015).

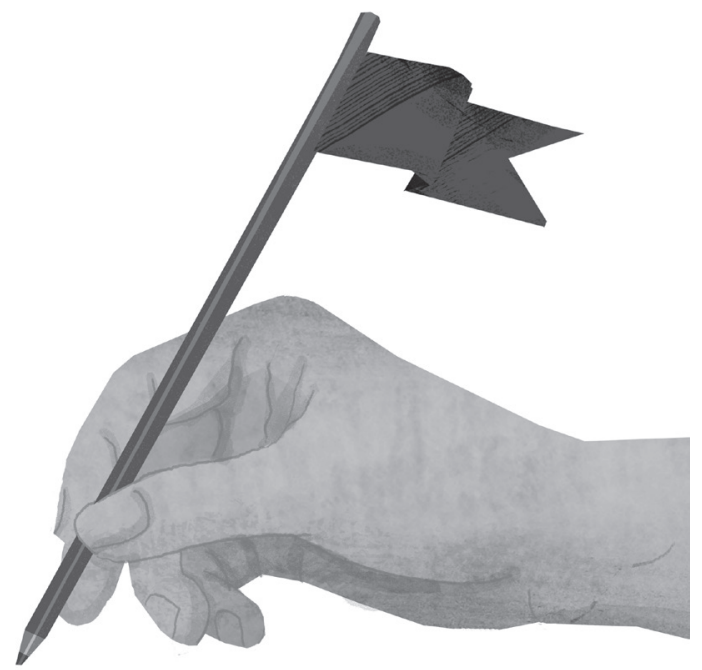

For University of Edinburgh staff, Edinburgh Research and Innovation hold a dossier of successful grant applications and funding guides: http://www.ed.ac.uk/researchsupport-office/toolkit-for-applicants. Staff in the College of Arts, Humanities and Social Sciences could consider applying for a mid-career research fellowship to get mentoring and feedback on grant writing - talk to your director of research. 